This PDF is a selection from a published volume from the National Bureau of Economic Research

Volume Title: Price Index Concepts and Measurement

Volume Author/Editor: W. Erwin Diewert, John S. Greenlees and Charles R. Hulten, editors

Volume Publisher: University of Chicago Press

Volume ISBN: 0-226-14855-6

Volume URL: http://www.nber.org/books/diew08-1

Conference Date: June 28-29, 2004

Publication Date: December 2009

Chapter Title: Incorporating Financial Services in a Consumer Price Index

Chapter Author: Dennis Fixler

Chapter URL: http://www.nber.org/chapters/c5079

Chapter pages in book: (239 - 266) 


\title{
Incorporating Financial Services in a Consumer Price Index
}

\author{
Dennis Fixler
}

\subsection{Introduction}

In recent years, the use of financial services by consumers has grown, with technological advances in both computers and telecommunications as well as with product innovation by financial firms. The national accounts measures of consumption include many financial services and as part of the comprehensive revision to the national accounts released in December 2003, the Bureau of Economic Analysis (BEA) improved its measure of the consumption of bank implicit financial services. However, the inclusion of financial services in a consumer price index has occurred to only a limited extent. Two complications are often cited that stand in the way of expanding the coverage of financial services. First, financial services involve activities that could be viewed as income generating and thus they are generally deemed outside the domain of such indexes. Second, financial service prices contain both explicit charges and implicit charges - the latter creates the problem of what value to place in the price index and this problem was the focus of the improvement by the BEA in its measure of financial services consumption.

Setting the domain of a consumer price index (CPI) involves a determination of the underlying purpose of the index. Most statistical agencies base their consumer price indexes on the cost of living (COL) conceptual

Dennis Fixler is chief statistician of the Bureau of Economic Analysis, U.S. Department of Commerce.

I am greatly indebted to George Smith and Gabriel Medeiros for their extensive work on compiling the indexes presented in the chapter. I also thank Susanto Basu, John Greenlees, Brent Moulton, Jeremy Nalewaik, and Marshall Reinsdorf for their comments. The analysis and comments solely reflect the view of the author and not necessarily those of the U.S. Bureau of Economic Analysis or the U.S. Department of Commerce. 
framework. ${ }^{1}$ That framework is not usually constructed with money or other financial assets in the utility function. The placement of money in a utility function has a long history in the literature and its justification rests on the fact that money facilitates transactions and provides a way of intertemporal transfers. ${ }^{2}$ However, Alchian and Klein (1973) argued that assets in general should be placed in the utility function in order that a CPI should provide a better measure of inflation under the COL framework. More specifically they argued that assets must be included to obtain a meaningful answer to the question, "Does the individual need more or less money to remain at the same level of satisfaction?" (186).

Another way to place financial assets in the domain would be to view them as though they were durable goods that provide implicit services that attend their holding. This is the view of the user cost of money approach, developed by Donovan (1978), Diewert (1974), and Barnett (1978). ${ }^{3}$ The precedent for putting such a framework in a CPI has already been set by the common treatment of housing in CPIs, which imputes a rental value of the services received from owner-occupied housing.

Both of these perspectives of financial services relate to a multiperiod analysis rather than the single period analysis in the standard cost of living framework. Pollak (1975) pointed out that there are several difficulties in constructing a multiperiod Cost-of-Living Index: futures markets are not always available, expectations about the future do not hold with certainty, and capital markets are not perfect. One way to handle the multiperiod problem in the context of the Cost-of-Living Index is to treat a single time period as a subindex of the multiperiod problem and apply the single period analysis. Similarly, Barnett (1980) constructs a multiperiod optimization problem for a consumer on the basis of separability of financial assets from other goods and services and shows that the optimization problem regarding financial assets can be reduced to a one period problem. Accordingly, this chapter also focuses on the one period problem; the attention is on the consumption of financial services within the period being considered.

Consumers purchase many types of financial services that are concomitant with financial assets and liabilities. The inclusion of such services in a CPI rests on their not being tied to a future receipt of money. For example, the purchase of automobile insurance is commonly included in CPIs, as are other forms of property and casualty insurance. Yet the purchase of life insurance is not included because it is viewed as both an intertemporal transaction, in the sense that the contract concerns the future transfer of a sum of money to others and as a tantamount purchase of an annuity, especially in the case of whole life insurance. Similarly, professional fees that are

1. See National Research Council (2002).

2. See, for example, Patinkin (1965).

3. As in the case of capital equipment, the idea is there is a flow of services that is received from a stock and the value of the services is given by the user cost of capital. 
associated with financial management, such as accounting, are included in CPIs, while fees for services such as financial advice, or portfolio management are generally excluded. ${ }^{4}$ However, this notion is inconsistent with the fact that the purchase of financial services by a consumer is consumption in the current period even though the purpose of the services is to increase income in subsequent periods. Therefore, these services should be included in the domain of a CPI. In principle, all financial services should be candidates for inclusion in a CPI.

As previously mentioned, setting the boundary of a CPI domain is only part of the complication of including financial services; the valuation of these services is sometimes not straightforward. This is especially true in the case of bank-provided financial services, for which there is no observable charge. Thus, a method of imputing the price of these services must be chosen.

Section 6.2 sets out more of the theory of incorporating financial services into a consumer price index. To give an idea of what a financial service component of a CPI might look like, section 6.3 presents three financial service price indexes that are constructed from data in the Personal Consumption Expenditures (PCE) component of the national accounts. Though the PCE price index is not based on a conceptual model of consumer behavior as is the CPI (as is typically compiled by statistical agencies), it is hoped that the illustration may serve as a useful guide to those considering the incorporation of financial services in a CPI. Section 6.4 provides a summary and conclusions.

\subsection{Theory}

Consumers are viewed as having a utility function that contains goods and services, inclusive of financial services. Woolford (2001) uses the following definition of financial services in discussing their incorporation into the Australian CPI: financial services are the services associated with the use, acquisition, or sale of financial and real assets. ${ }^{5}$ This definition clearly captures expenditures on fees for portfolio management and investment advice. $^{6}$

4. Further discussion on the inclusion of financial services in the domain of a CPI can be found in Woolford (2001), Triplett (2000), and chapter 10 in International Labour Organization (2004) - a new version of their CPI manual.

5. This definition is also used in the discussion of financial services in International Labour Organization (2004).

6. The definition, however, does not distinguish between intermediate and final demand and such a distinction is important when considering the acquisition of a home and the related expenses. More specifically, some of the financial services involved in the purchase of housing are not classified as consumption in the U.S. national accounts and in the accounts of most other countries. In the United States, a notional business is set up for households that produce housing services from the investment in a house and these services are resold to the homeowner. 
Though the purchase of financial services is tied to the acquisition or holding of a financial asset or liability, either of which can be cast as a financial product, the multiperiod dimension of the demand for these is not considered here; the focus is on the per period consumption of the attending financial services. ${ }^{7}$ One can think of the consumer as having both longterm and short-term optimization problems that are linked. In the long-term problem, the consumer plans consumption over time-the intertemporal optimization problem. This dynamic problem considers both consumption and the expected changes in income available for consumption. The shortrun problem concerns the purchase of goods, services and assets/liabilities in a particular period, given the income and stock of financial assets available in the period. ${ }^{8}$ The short-run problem therefore concerns the period purchase of any financial services that attend financial assets. For example, a depositor purchases the record keeping and safe keeping services implicit in the holding of deposits in the period that the deposit is held. Similarly, a portfolio manager is paid for his services (carrying out transactions and providing advice) in the period that they are provided. The fact that there are intertemporal considerations underlying the holding of deposits or a portfolio does not preclude the consideration of the purchases of the attending financial services in any period. The purchase of any asset, however, would not be included in the period measure of consumption. ${ }^{9}$

Banks provide numerous services; some have explicit charges and some have implicit charges. The valuation of the prices for implicit services is the major difficulty in forming a comprehensive set of bank services prices because many important financial services are provided implicitly. For example, the services of record-keeping and safekeeping are implicitly provided to depositors and there are no explicit charges for these services.

The user cost of money approach developed by Diewert (1974), Donovan (1978), and Barnett (1978) is one way to impute the price of the implicit

It follows that in the United States, the fees paid to real estate agents are not consumption, part is allocated for the purchase of land and is considered an intermediate purchase, and part is allocated for the purchase of the structure and is classified as residential fixed investment; Woolford (2001), in contrast, lists real estate broker services as part of the Australian CPI.

7. Some might be concerned that the definition of financial services transforms the CPI from an expenditure basis to a use basis, which affects the price recorded for goods and services that span more than one time period. For example, under the current expenditure approach the price of a purchased auto would be recorded in the CPI while under a use approach some estimate of the per-period value of the service flowing from the auto would be incorporated in the index. But this is not the intent. The focus is on the financial services inextricably attached to the asset/liability. One cannot purchase a deposit product without purchasing record-keeping and safekeeping services.

8. In the standard one period model underlying the cost of living framework, the dual optimization problem is employed: consumers minimize expenditures to achieve a given level of utility in the period in which the consumption is to take place.

9. Schreft (2006) describes how even the choice of a payment instrument can be the object of an intertemporal consumer optimization problem. 
financial services. ${ }^{10}$ This approach is taken below and it is identical with the one that underlies the user cost approach for implicit banking services that BEA implemented in the comprehensive revision released on December 10, 2003. ${ }^{11}$

The key to incorporating financial services is characterizing their prices so that they include both the implicit and explicit charges, which are viewed as given to consumers. The user cost of money approach focuses on the cash flow resulting from the purchase of the financial product. For deposit products, the cash flow consists of an initial deduction from cash holdings and a return of the cash plus an interest component at the end of the time period. Let $D$ denote the deposit amount, $r_{D}$ the interest rate paid on deposits and $\rho$ the risk-free interest rate that serves as an opportunity cost of money. The cash flow without any explicit service fee is given by:

$$
-D+\frac{\left(1+r_{D}\right) D}{1+\rho}=\left[\frac{\left(r_{D}-\rho\right)}{1+\rho}\right] D ;
$$

this assumes no withdrawals during the period. ${ }^{12}$ The bracketed term on the right-hand side of the equality is the user cost of deposits from the consumer perspective. This expression says the difference between the reference rate and the deposit interest rate represents the implicit price paid by the depositor for the uncharged-for financial services. The explicit fee component can be considered in one of two ways. One could include a service fee in the previous expression, but it would have to be defined on a per dollar basis, which may be counter to the way that the actual charge is assessed. For example, the charge for certifying a check is usually a flat fee that is independent of the amount of the check. Alternatively, explicit service fees can be treated separately and that is the approach used in the example presented in section 6.3.

The deposit user cost price above is the negative of the user cost price of deposits from a bank's point of view; the one used in the 2003 comprehensive revision to the national accounts (see Fixler, Reinsdorf, and Smith [2003]). ${ }^{13}$ The sign difference results entirely from the fact that the asset and liability

10. See Fixler and Zieschang (2001) for a discussion of the application of the user cost approach to CPIs.

11. See Moulton and Seskin (2003) and Fixler, Reinsdorf, and Smith (2003) for a discussion of the changes in the measure of implicit banking services in the national accounts that were implemented in the comprehensive revision.

12. Barnett (1978) uses a dynamic optimization model to derive the user cost of money prices.

13. In the computation of the user cost prices from bank data it is quite frequently found that for deposit products, $\left(\rho-r_{D}\right)>0$, implying that the bank treats the deposit product as an output. In the consumer problem this means that the parenthetical term above is negative. The negativity is consistent with the notion of a payment for financial services by consumers and the positive sign for the bank is indicative of a receipt. 
designations for the consumer are the reverse of that for the financial intermediary; a deposit product is an asset to the consumer but a liability to the supplying bank. In keeping with the assumption that consumers are price takers, the form of the user cost price for deposits will be that charged by a bank and the discount factor is suppressed:

$$
p_{D}=\rho-r_{D} .
$$

The previous characterization of the deposit price is consistent with Dick (2002), who found that the demand for deposit services is based on both the service fee and interest rates. ${ }^{14}$

A similar analysis applies in the case of loans. From a consumer's perspective a loan is a liability that provides an amount $L$ at the beginning of the period and at the end of the period requires the payment of $L$ plus interest $r_{L} L$, where $r_{L}$ is the loan interest rate. From the financial intermediary's perspective, however, the cash flow is the exact opposite, as the loan is an asset that provides earnings. The user cost price of the loan from a bank's perspective is thus:

$$
p_{L}=r_{L}-\rho .^{15}
$$

The interest rate differential in the previous loan price captures the idea that consumers go to banks because it is relatively easier to convince a bank of one's creditworthiness than the market (or even one's relatives) and the consumer pays the bank a fee for its assumption of this credit risk. Equation (2) is the implicit price of loan services. The explicit price for loan services are separate, as in the case of deposit products.

In the previous characterizations of the prices of the loan and deposit implicit services, the idea is that the transaction is in effect repeating itself in each period. In the case of loans, the implicit charge represented by the interest rate differential is a per period charge because if the loan continues, that is, if it is neither paid-off or canceled by the bank, then the borrower pays for the continued assumption of the credit risk by the bank for the outstanding balance. Similarly, if the depositor leaves money on deposit then deposit services are repurchased in the period.

The user cost price concept can be applied to numerous financial services. In countries where there is universal banking (one-stop financial service centers) the set of financial products is quite large and thereby creates more possibilities for implicit financial services. The extension of the user

14. Furthermore, it is not just the deposit rate that is important but also the loan rateevidently consumers consider the potential costs of having to switch to another bank in order to obtain a loan.

15. Holding gains or losses can also be included here and in principle in the deposit user cost as well. In the national accounts the inclusion of such values as part of valuation of financial services is currently being studied. 
cost approach to different kinds of financial services is in Schreyer and Stauffer (2002).

A key component of the user cost price is the reference rate or benchmark rate. In theory, this rate should represent an opportunity cost of funds that guides decision making with respect to either the demand or supply of financial products. As can be seen from the discussion of the mirror images between the consumer user cost price and the financial intermediary user cost price, it is assumed that both banks and consumers have the same reference rate. ${ }^{16}$ It is also assumed that this single reference rate applies to all financial products. To illustrate, instead of depositing funds in a bank, consumers could purchase Treasury bonds. Though they would earn a higher interest rate by doing so they would forgo transaction services and some liquidity. From a bank's perspective, deposited funds can be invested in Treasury securities - they provide a credit-risk-free source of investment income and a source of liquidity. This role for Treasury securities implies that they serve as an alternative to making a particular loan. Thus, the difference between the loan rate and the reference rate reflects the credit risk associated with the borrower; if the borrower did not have any credit risk then in principle he should be able to borrow at the reference rate. ${ }^{17}$

There are several interest rates that have been mentioned as candidates for the reference rate and as the previous examples indicate, U.S. Treasury rates are good candidates because they are default risk-free and available to all. In the European Union, Eurostat requires an interbank rate. Though Fixler and Zieschang (1992) show that quantity indexes are robust with respect to the selection of the reference rate, the selection of the rate does affect the nominal level of financial services.

The inclusion of interest rates in the user cost prices raises the general question of whether to use book or market rates. Some considerations are: (a) individuals hold assets and liabilities over time so that the actual flow of interest expenses and receipts can be different from the one that is consistent with the market rate for any specific period; (b) the detail available on the financial products held by individuals may not permit an assignment of a correct market rate; and (c) there is a national accounting convention to use book rates instead of market rates. Accordingly, interest rates here are computed in a way that reflects book rather than market values. More specifically, all interest rates used in the following example are computed by dividing some interest flow (receipt or expense) by the stock of the cor-

16. Barnett (1995), for example, also assumes that one benchmark rate applies to all agents; in his model the benchmark asset provides no services other than its yield.

17. Some may argue that the reference rate should be adjusted for the default risk of the borrower to properly measure the credit service that is being provided. However, if a bank determines the loan rate on the basis of the borrower's default risk then such an adjustment may produce a downward bias in the valuation of the service being provided. 
responding financial product at a point in time. ${ }^{18}$ This method of computation implies that all of the interest rates used in the user cost prices take into account the different maturities of the underlying financial product. For example, the computed reference rate reflects all the maturities of U.S. Treasury securities held by banks and the computed loan rate reflects the maturities of outstanding loans. ${ }^{19}$

As is well known, the nominal interest rate in any period is directly related to the expected rate of inflation in that period, which implies that the interest rate-dependent financial service prices can be affected by inflation. As a result, the user cost prices are deflated by a general price index; the gross domestic purchases chain price index is used to deflate the user cost price relative between $t$ and $t-1$. The appendix illustrates how inflation rates are captured by the unit value interest rates.

In addition to the general price level changing over time, the characteristics of financial products change over time and thereby create a need for quality adjustment as well. For example, suppose that in period $t$ a deposit product has a minimum balance requirement and a service fee $s$ and in period $t+1$, this minimum balance requirement is dropped and the service fee increased. Because there is a change in the quality of the service - the customer has more of the amount of deposit available to him, one would want to adjust the change in $s$ for the change in the quality of the service. ${ }^{20}$ Fixler and Zieschang (1999) demonstrate one way of adjusting the user cost prices for changes in the quality of financial services. The price indexes constructed in the next section are not adjusted for change in the quality of the financial services. This omission largely derives from the absence of a readily available set of data that contains the information needed. More specifically, information on transaction restrictions (such as minimum balance requirements or number of checks allowed per month) or the number of ATMs is neither collected by the regulatory authorities, the prime source of data, nor by the Bureau of the Census in the Economic Census for banks. However, inasmuch as the purpose of the example in the next section is to show how a financial services component of a consumer price index might be constructed and how the resulting indexes behave rather than provide augmentations to official estimates, the absence of quality adjustments does not detract from the analysis. Of course, any official implementation of a

18. As described in Fixler, Reinsdorf, and Smith (2003), the change in the valuation of implicit services in the national accounts also employed a unit value computation of interest rates.

19. In the July 2005 annual revision the computation of the reference rate was changed to eliminate mortgage-backed securities, which have recently become risky because of reporting irregularities from the issuing firms.

20. In some instances the characteristics of the financial product and the financial service coincide. If the characteristic set of a deposit product were amended to include Internet banking, then there would simultaneously be a new form of transaction service. However it is viewed, a quality adjustment would be necessary. 
financial services component to a consumer price index must examine the issue of quality adjustment.

\subsection{A PCE-based Financial Services Price Index}

To illustrate what a financial service component of a CPI might look like, data from the BEA's Personal Consumption Expenditures (PCE) are used to construct such an index. Because the purpose of PCE is to record expenditures of consumers (and nonprofit institutions serving households) as part of the overall measure of economic activity, PCE is not based on a cost of living framework and includes many types of expenditures that are associated with income generation. Table 6.1 lists the financial services included in PCE and provides their average share of the total for these financial services in 2000. Most of the listed financial services are components of the personal

Table 6.1

The set of financial services

Equities commissions

Brokerage charges and investment counseling

1. Exchange listed equities ( 2.4 percent)

2. Market making in over-the-counter equity securities (1.3 percent)

3. Other equity securities, including specialists on registered exchanges and dealer trading (0.97 percent)

4. Listed options transactions ( 0.22 percent $)$

5. All other securities transactions (4.6 percent)

6. Broker charges on mutual fund sales (1.8 percent)

7. Trading profits on debt securities ( 0.22 percent)

8. Trust services of commercial banks ( 0.47 percent)

9. Investment advisory services of brokers (2.4 percent)

10. Commodities revenues ( 0.43 percent)

11. Investment counseling services (3.1 percent)

Bank service charges, trust services, and safe deposit box rental

12. Commercial bank service charges on deposit accounts ( 3.2 percent)

13. Commercial bank fees on fiduciary accounts ( 2.5 percent)

14. Commercial bank other fee income ( 3.3 percent)

15. Charges and fees of other depository institutions ( 2.6 percent)

Services furnished without payment by financial intermediaries

16. Commercial banks (11.5 percent)

17. Other financial institutions (18.4 percent)

18. Expenses of handling life insurance and pension plans (17.2 percent)

19. Household insurance ( 0.69 percent $)$

20. Auto insurance ( 7.7 percent)

Health insurance

21. Medical and hospital insurance (12.2 percent)

22. Income loss insurance ( 0.3 percent)

23. Workers' Compensation ( 2.5 percent)

Note: Number in parentheses is the average share of Financial Services in 2000. 
business category within PCE while other financial services are classified in the category related to the service-for example, auto insurance is in the transportation category. These financial services totaled 559 billion dollars in 2000. There is some overlap with the services included in the U.S. CPI. In fact, the BEA uses the information regarding the explicit fees included in the CPI when computing real explicit bank services in PCE.

Most of the data that are used to compile the PCE components for bankprovided financial services come from the Reports of Condition and Income (the Call Reports) that banks have to file quarterly with the Federal Deposit Insurance Corporation. Because these data are bank reported, there is no identification of the buyer of the financial services and so allocations are made using the Federal Reserve's Flow of Funds Accounts data. For example, the household portion of bank implicit financial services is determined by looking at the household share of deposits and loans in the Flow of Funds data. ${ }^{21}$ In some cases it is straightforward to identify the purchaserfor example, personal loans can be confidently assigned to the household sector. These allocations change annually. The time period of consideration is $1987 \mathrm{Q} 1$ to $2002 \mathrm{Q} 4$. This period was selected because it is one in which the bank reporting requirements are relatively unchanged.

Though the December 2003 comprehensive revision to the national accounts, as described in Moulton and Seskin (2003) and Fixler, Reinsdorf, and Smith (2003), implemented a user cost of money approach to compute the nominal value of the implicit bank services, there was no change in the computation of real values or constant dollar measure of implicit bank services. The constant-dollar measure of banks' implicit output equals (a) the constant-dollar value of banks' total output, estimated by extrapolating the base-year (2000) current-dollar estimate of banks' total (both explicitly and implicitly priced) output by the BLS estimate of the growth in banks' total output less ${ }^{22}$ (b) the constant dollar real value of banks' explicitly priced output, estimated by deflating banks' service charges on deposit accounts and other noninterest income with the Bureau of Labor Statistics (BLS) CPI for checking account and other bank services and then adding an estimate of banks' real fiduciary activities based on the growth of the number of trust department discretionary accounts. This real implicit service output measure is then used to obtain an implicit price index (current dollar divided by constant dollar) for the implicit bank services. Observe that this price index does not directly relate to the user cost prices presented previously.

Similarly, Moulton and Seskin (2003) and Chen and Fixler (2003) describe

21. In the 2005 annual revision some adjustments were made to the set of deposit products that were considered to be consumer oriented. In particular, some large deposit products that arguably could be viewed as being more associated with businesses than with households were removed.

22. The BLS methodology for measuring bank output is explained in Kunze, Jablonski, and Sieling (1998). 
the changes in the nominal measure of property and casualty insurance output that were implemented in the comprehensive revision. These changes were the addition of premium supplements and the use of a measure of normal claims instead of actual claims; the nominal value of property and casualty insurance became premium plus premium supplement less normal claims. ${ }^{23}$ Again, the computation of real values was not altered. The computation of the real values generally involves the use of various components of the BLS' CPI and PPI programs to deflate premiums (and premium supplements) and (normal) claims components, the methods of deflation are not the same across the various lines of insurance. ${ }^{24}$ These price indexes are used to compute real values in terms of the base year and then these real values are used to compute an implicit price deflator, which is the price index published by BEA. ${ }^{25}$ Some might argue that a premium less claims-based measure of price is inappropriate for a CPI. It is beyond the scope of this chapter to discuss the merits of different approaches to measuring insurance services in a consumer price index. The purpose here is to present an example of such an index in the context of Personal Consumption Expenditures, which uses the premiums less claims-based measure of price.

Three financial service price indexes reflecting three different methods for estimating bank real implicit services are computed below: one is based on the current BEA procedure that uses an implicit price deflator, a second is an offshoot of the current method that separates depositor and borrower services and the third is a user cost based price index. In the first, the published BEA price indexes for all of the services listed in table 6.1 are used to form a financial services price index component for PCE. Many of the service prices included in these indexes are explicit charges. For the implicit services provided by banks as well as for auto insurance, the BEA published price indexes are actually implicit price deflators that reflect the changes in the computation of nominal values that were implemented in the 2003 comprehensive revision.

Because the financial services shown in table 6.1 are found in different categories of PCE, the corresponding implicit price deflators must be aggregated in some way. In keeping with the fixed-base nature of the indexes,

23. Premiums supplements are the income earned by the insurer from investing unearned premiums and unpaid claims and this income is attributed to policyholders. Normal claims are computed as a moving average of actual claims - the idea is that insurers base their pricing on expected rather than actual claims.

24. In the case of homeowner's insurance double deflation is used because of the availability of a BLS CPI on household insurance premiums for renters. However, automobile insurance is singly deflated by the CPI for motor vehicle insurance premiums. In the case of expenses for handling life insurance, the BEA uses a composite index of BLS measures of earnings - that is, the deflation is based on input prices.

25. The BEA recognizes that this method of deflation is limited and has on its research agenda improving the method of deflation. One aspect of that research will be the possible use of the PPI for property and casualty insurance, which already incorporates investment income in its price index. 
the aggregation is performed by using a Laspeyres-type aggregation-each implicit price deflator is weighted by its share of financial service expenditures in the base period. More specifically, let $I P D_{i}^{f_{s}}(t, 2000)$ be the implicit price deflator for the $i$ th financial services listed in table 6.1. The aggregate fixed weight price index for financial services is then:

$$
P_{F W}^{F i n S e r v}=\sum_{i} I P D_{i}^{f s}(t, 2000) s_{i, 2000}^{f_{s}},
$$

where $s_{i, 2000}^{f_{s}}$ is the share of the $i$ th financial service in the base year, 2000 .

Figure 6.1 shows the fixed weighted financial services price index in equation (3). It is compared to an aggregate PCE price index that is computed by weighting the PCE component prices by their shares in 2000, as done in equation (3). Clearly the financial services index is more volatile, but that volatility does not appear to affect the overall PCE because the 2000 share of the financial services subset in table 6.1 is approximately 8 percent. Interestingly, the share remains approximately constant throughout the period examined.

Under the current method for determining the real value of implicit banking services a total is computed and then allocated to deposit and loan services. This allocation is made according to the nominal shares of implicit deposit and borrower services. A subsequent allocation of implicit deposit and borrower services is made to households and businesses according to their respective shares of deposits and loan balances. Thus, the sector allo-

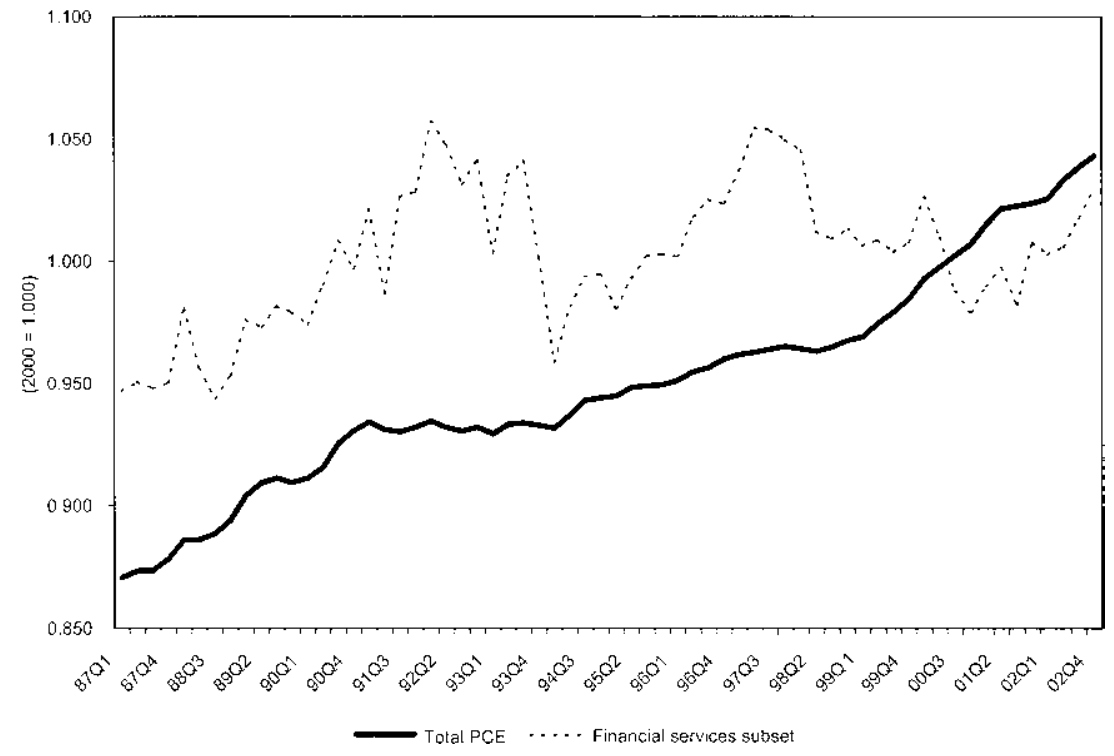

Fig. 6.1 Fixed-weight price indexes (IPD), PCE, financial services subset 
cation of nominal implicit services reflects both changes in user costs for depositor and borrower services and changes in sector shares of nominal deposit and loan balances. Because about 60 percent of the deposits at commercial banks are owned by persons and given that this percentage has not changed much over time, an implication of the current procedure is that a change in the user cost price of deposits will affect the share of real implicit deposits services allocated to households. To illustrate, suppose that the user cost price of deposits increases, ceteris paribus, and results in an increase in the share of nominal implicit deposits services from 65 to 70 percent. Using the 60 percent value for household deposits, the share of real implicit deposits allocated to households will increase from 39 percent to 42 percent. Thus, the real implicit deposit services consumed by households will increase because of the increase in the user cost price of deposits.

One way to remove the influence of changing user costs on the real consumption of implicit services would be to perform the quantity extrapolation by type of service-depositor and borrower services. ${ }^{26}$ This second method is possible because the BLS measure distinguishes between these two types of services. More specifically, estimates of the overall real implicit depositor services are determined by extrapolating the base-year estimate of total (implicit and explicitly-priced) depositor services with the deposit component of the BLS quantity index and then subtracting a deflated measure of explicitly-priced depositor services. The amount of the personal consumption of real implicit depositor services is determined by the share of nominal deposit balances owned by persons. Therefore, changes in real personal consumption of implicit depositor services reflect changes in the BLS quantity index, changes in deflated measures of explicitly-priced depositor services, and changes in the personal sector's share of nominal deposits, but not changes in the user cost of deposits. The same approach is applied to borrower services.

Figure 6.2 illustrates the price indexes (implicit price deflators) that result from these more detailed and published methods of quantity extrapolation. The extrapolation by type has a large influence on total PCE after about 2000Q3 that reflects its greater influence on financial services at about that time. Note that the pattern of the financial services index does not change with the quantity extrapolation by type.

Figure 6.3 shows the effect of the change in the method of quantity extrapolation on the banks' implicit services component. Observe that the implicit depositor services price index for banks, when the quantity extrapolation is by type, has a substantial positive impact on total implicit services by type after $2000 \mathrm{Q} 3$. It should be noted that approximately 80 percent of the implicit services consumed by persons are deposit services. Accordingly, when treated separately the influence of implicit depositor services will be

26. This procedure was suggested by George Smith. 


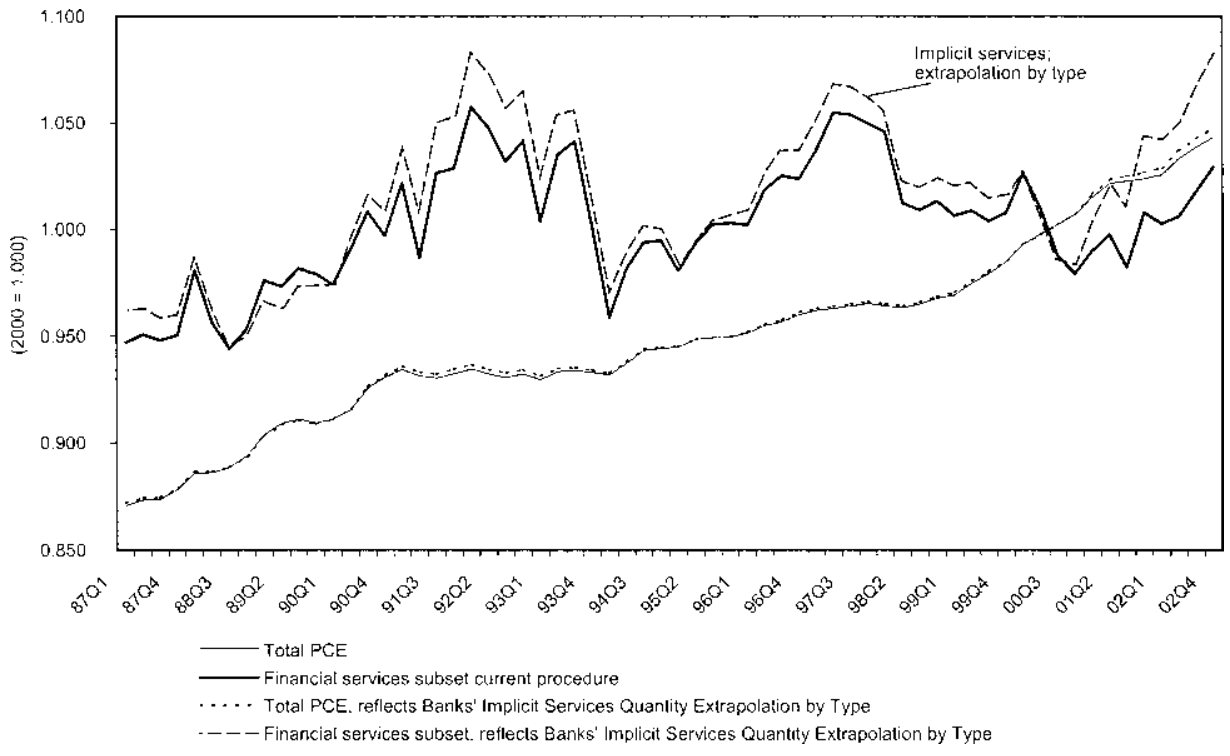

Fig. 6.2 Comparison of fixed-weight price indexes for financial services and total PCE

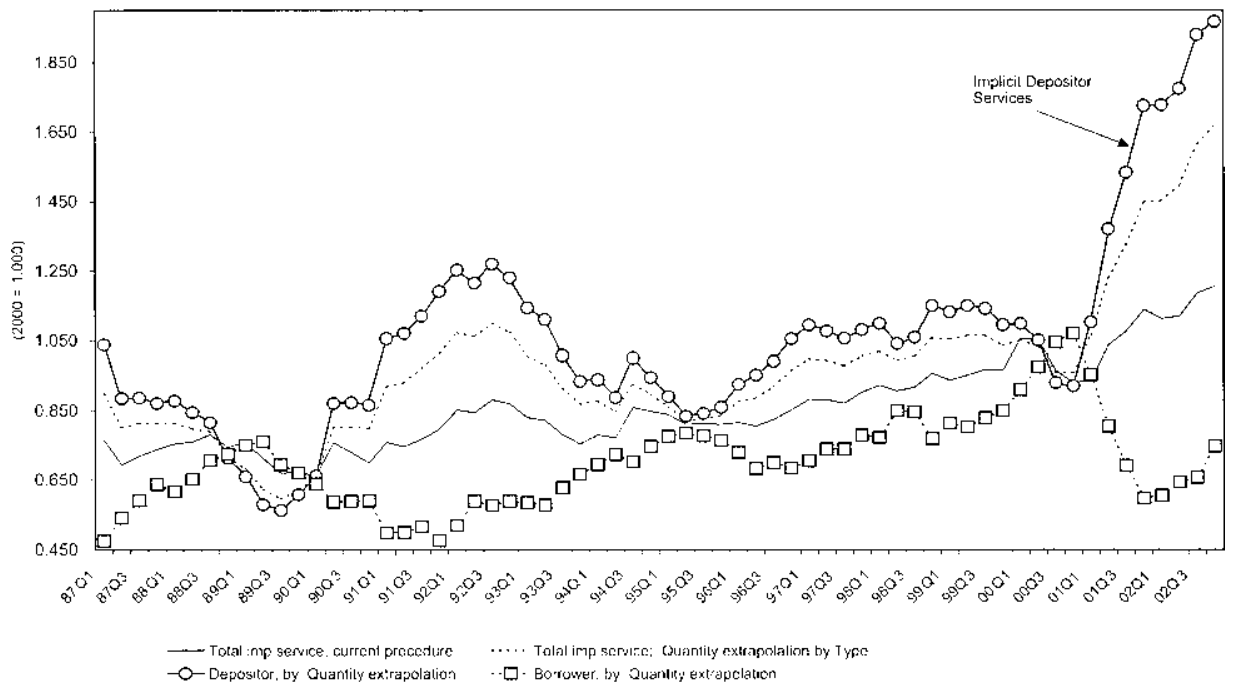

Fig. 6.3 Price indexes (implicit price deflators) for total implicit services: Two methods of quantity extrapolation 
more pronounced; the joint treatment of depositor and borrower services obscures the relative weight difference.

A third method of computing bank real implicit service output uses the user cost prices in equations (1) and (2) to construct a Törnqvist financial service price index. The Törnqvist formula is used for mathematical simplicity; it easily allows for the isolation of subindexes and allows for an easy rescaling of expenditure shares. Furthermore, because the Törnqvist formula and Fisher index formula used by the BEA are both superlative, there will be no loss in the ability to compare the movements of this index with PCE chain Fisher price index published by the BEA. ${ }^{27}$ The general form of a Törnqvist price index is given by

$$
P_{\text {Torng }}(t, t-1)=\prod_{i}\left(\frac{p_{i}^{t}}{p_{i}^{t-1}}\right)^{0.5\left(s_{i}^{t}+s_{i}^{t-1}\right)},
$$

where $p_{i}$ is the price of the $i$ th good or service and $s_{i}$ is the expenditure share of the $i$ th good.

The financial services Törnqvist price index contains two subindexes: one containing the explicit financial service prices (some bank services, brokerage services, and insurance) and one containing the implicit financial service prices for implicit services (particularly some deposit and loan services provided by banks). For the first component, the Törnqvist index formula is used; the prices are derived from actual charges and the shares are the expenditure on these services as a fraction of the expenditures on all of the financial services listed in table 6.1. This index is denoted by $P_{\text {Tornq }}^{\text {expit }}(t, t-1)$.

For the implicitly priced services, the following Törnqvist formula is used

$$
P_{\text {Tormq }}^{\text {implicit }}(t, t-1)=\prod_{i}\left[\frac{p_{L i}^{t} / p_{L i}^{t-1}}{\delta(t, t-1)}\right]^{0.5\left(s_{L i}^{t}+s_{L i}^{t-1}\right)} \prod_{j}\left[\frac{p_{D j}^{t} / p_{D j}^{t-1}}{\delta(t, t-1)}\right]^{0.5\left(s_{D j}^{t}+s_{D j}^{t-1}\right)},
$$

where $p_{L}$ identifies loan prices, as in equation (2), and $s_{L}$ shares (implicit loan services as a fraction of total financial services) and $p_{D}$ identifies the deposit prices, as in equation (1), and $s_{D}$ shares (implicit deposit services as a fraction of total financial services). There are 4 loan products and 11 deposit products. The term $\delta$ is given by

$$
\delta(t, t-1)=\frac{\text { Gross Domestic Purchases Price Index }(t, 2000)}{\text { Gross Domestic Purchases Price Index }(t-1,2000)},
$$

27. See Diewert (1976) for the concept of a superlative index. Diewert (1978) showed that the numerical difference among commonly used superlative index number formulas is very small, on the order of .001 index points. 
and is intended to adjust the user cost prices for general inflation. In the following example, $\delta(t, t-1)$ is based on a four quarter moving average of the published Gross Domestic Purchases Price Index. ${ }^{28}$

The complete financial services price index is thus given by

$$
P_{\text {Tornq }}^{\text {Finserv }}(t, t-1)=P_{\text {Tornq }}^{\text {expliti }}(t, t-1) \cdot P_{\text {Tornq }}^{\text {implicit }}(t, t-1) .
$$

This bilateral index is a component of the chain Törnqvist price index that is used to compute the financial service price index for more than two periods.

Figure 6.4 shows the relationship among the book value based interest rates used to construct the user cost prices. Note that there are downward trends in all of the interest rates during the 1990 to 1991 and 2001 recessions, despite these rates not being market rates.

Figure 6.5 shows a comparison between the chain Törnqvist financial services price index and the published chain Fisher PCE price index. Though the financial services price index is more volatile, the volatility of those prices does not appear to present itself in the overall PCE price index because, as noted earlier, the financial services subset of PCE amounts to approximately 8 percent of PCE for the period under consideration.

Figure 6.6 presents a closer examination of the movements of the components of the Törnqvist financial services price index. The overall steady increase in the total financial services price index is driven by the steady increase in the insurance subset that contains the insurance services listed in table 6.1. The insurance subset amounts to approximately 40 percent of financial services in 2000, with the share not varying much over the considered time period. Observe that there is a decrease in price in 2001Q3 owing to the terrorist attacks on September 11, 2001. ${ }^{29}$ The explicit fees component share in 2000 was approximately 18 percent and remained fairly constant. Bank implicit services had a share of about 12 percent, with 9 percent deriving from depositor services and 3 percent from borrower services. Observe that some of the movement in the implicit financial services index influences the movement of the overall financial services index.

Figure 6.7 presents a closer look at the movement of banks' implicit financial services by presenting the depositor and borrower price indexes

28. Gross Domestic Purchases is defined as the market value of goods and services purchased by U.S. residents, regardless of where those goods and services were produced. It is measured as Gross Personal Consumption Expenditures plus Gross Private Domestic Investment plus Government Consumption Expenditures and Gross Investment. Because this price index contains financial services it may appear that its use as a deflator for the user cost price relative is problematic. Based on an examination using fixed weight implicit price deflators, the inclusion of financial services has a very small impact on the deflated value of the user cost price relative. This small influence derives from the fact that the financial services in table 6.1, on average, amount to about 5 percent of nominal Gross Domestic Purchases.

29. This reduction would have been larger without the change in the measure of insurance implemented in the December 2003 comprehensive revision; see Chen and Fixler (2003) for a detailed description of that change. 


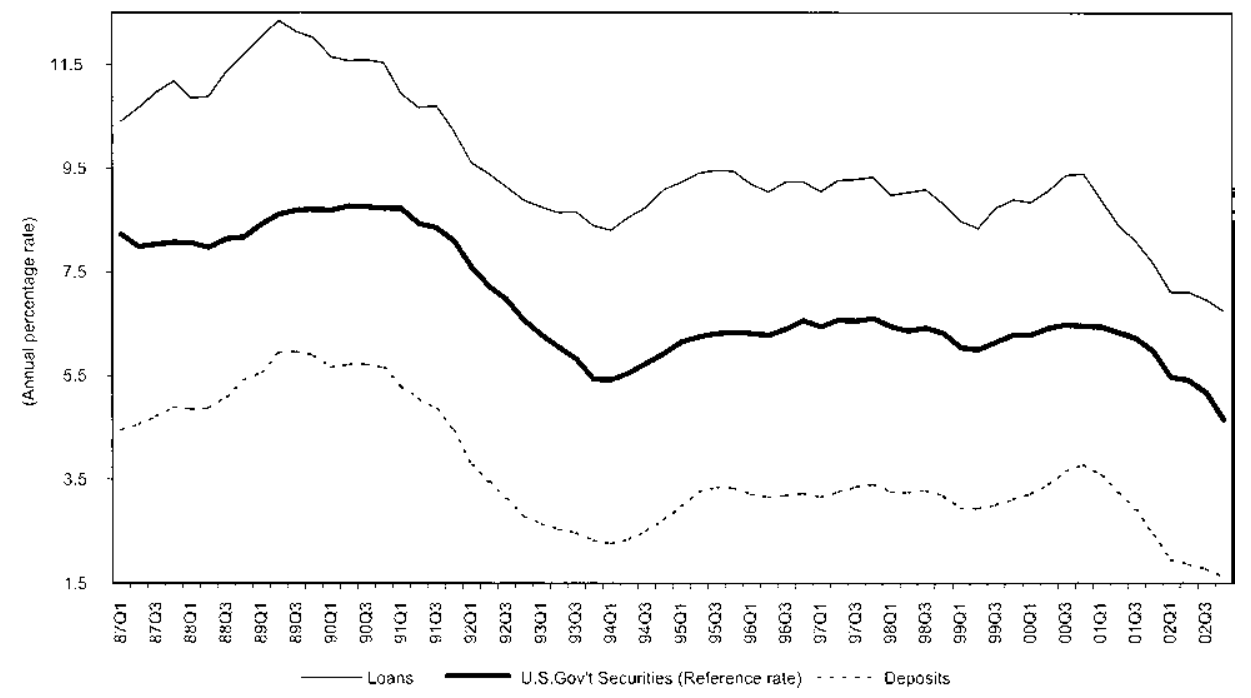

Fig. 6.4 Average interest received and paid by banks, book values

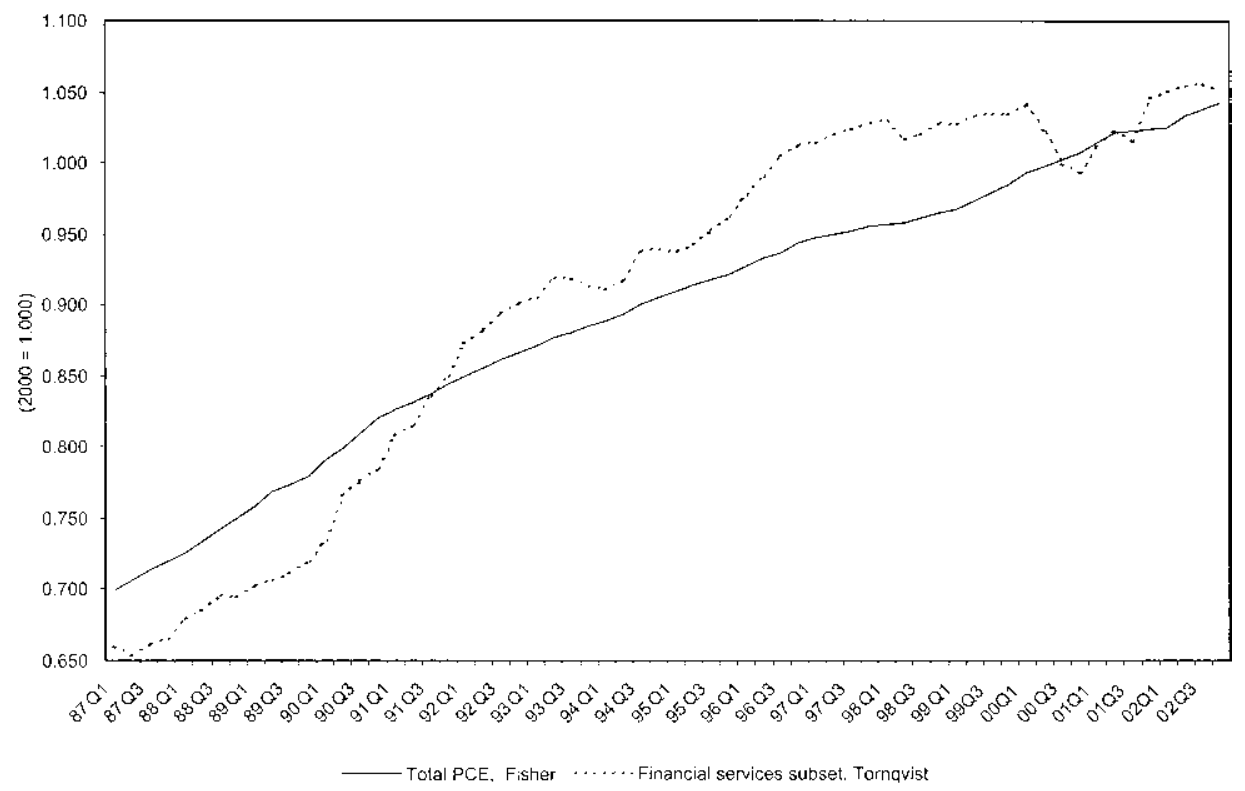

Fig. 6.5 Comparison of published PCE price index with Törnqvist user cost based financial services price index 


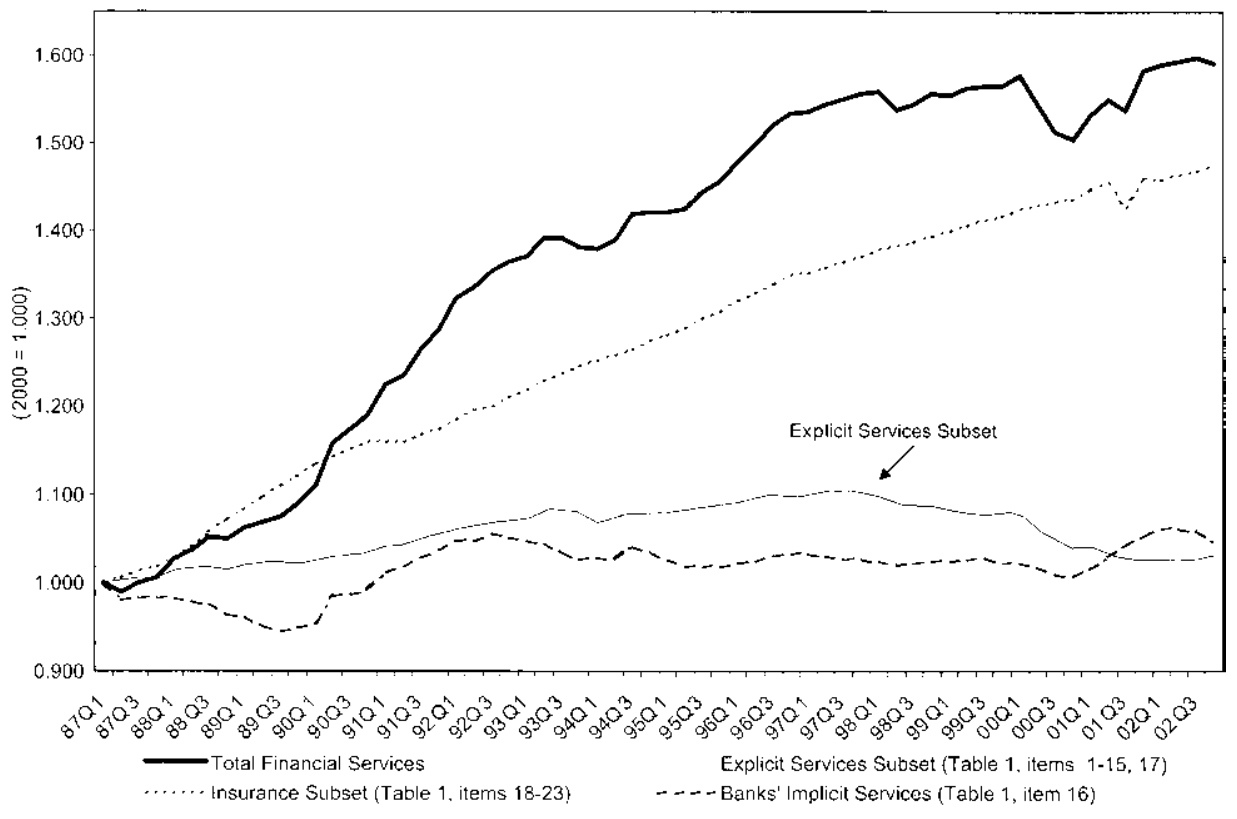

Fig. 6.6 Törnqvist chained price indexes for financial services

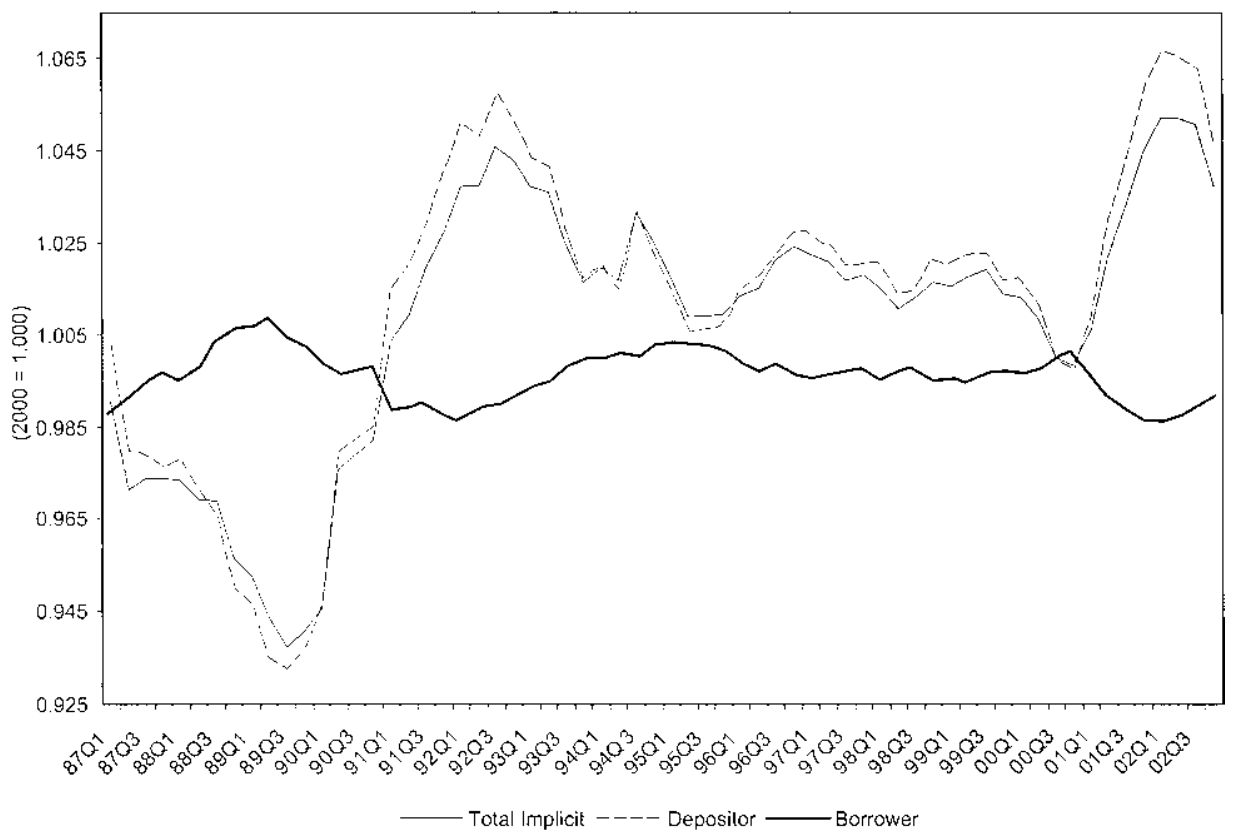

Fig. 6.7 Törnqvist price indexes: Total implicit, depositor and borrower services 
separately. Clearly the implicit services subindex follows the movement in the depositor series and this is due to the fact that depositor services range from 60 to 90 percent of implicit services while borrower services range from 10 to 40 percent. In 2000 Q 4 depositor services start to rise toward their peak of 90 percent while borrower services move toward their low of 10 percent. Looking at figure 6.4 one can see that during this time all of the interest rates are falling but that rate of decline in deposit rates is relatively great, which serves to increase the user cost price of deposits. Note that the decrease in deposit rates in the early 1990s also contributed to the large increase in the deposit user cost price index.

Figures 6.8 and 6.9 compare the movement of the user cost prices of deposit and borrower implicit services with the respective implicit price deflator. Figure 6.8 shows the user cost price of deposits with and without its deflation by a four quarter moving average of the Gross Domestic Purchases price index. ${ }^{30}$ The implicit price deflator for depositor services is computed by dividing the nominal value of implicit depositor services by a corresponding real value that reflects quantity extrapolation with the BLS deposit output index. Though the levels are different the movement in all three series is very similar. This result derives from the fact that both the amount of deposits, which together with the user costs yields the nominal measure, and the quantity extrapolator do not change much over the period. In other words, the variation in all three series is due to the variation in the user cost price. ${ }^{31}$ The borrower counterparts for these series are presented in figure 6.9 and the same analysis applies. ${ }^{32}$ Though the patterns in the depositor and borrower services prices are nearly the same among the different measures of depositor and borrower service prices, the difference in levels affect the attending quantities of depositor and borrower services.

Figures 6.10 through 6.14 present the quantity indexes that correspond to the price indexes discussed previously. The quantity indexes are computed by taking the quantity in year $t$ and dividing by the quantity in 2000. Figure 6.10 shows that the quantity index for total PCE is not changed when the quantity extrapolation is done separately by type of service instead of by a single combined service - the two quantity index series effectively lie on top of each other. This result seems to be due to the small weight of financial services subset in total PCE. Observe that the two financial services indexes differentiated by the method of quantity extrapolation show different levels, though the paths are very similar. Figure 6.11 focuses on the fixed weight

30. In any period the user cost deposit price is computed as a deposit share weighted sum of the individual deposit user cost prices. The value without deflation is the user cost price indexes with $2000 \mathrm{Q} 3=1$.

31. The movement in the moving average of the Gross Domestic Purchases price index is fairly stable.

32. As in the case of deposits, the borrower user cost price is a loan share weighted sum of the individual loan user cost prices. 


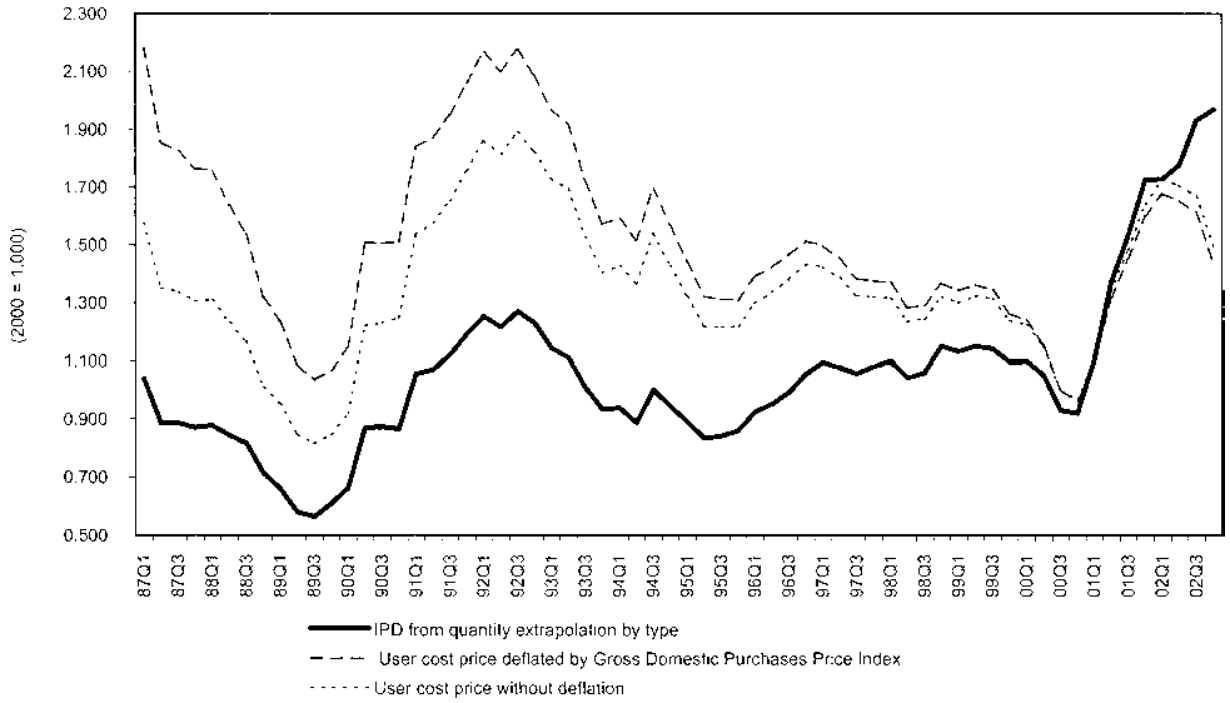

Fig. 6.8 Comparison of depositor service prices: Implicit price deflator versus user cost

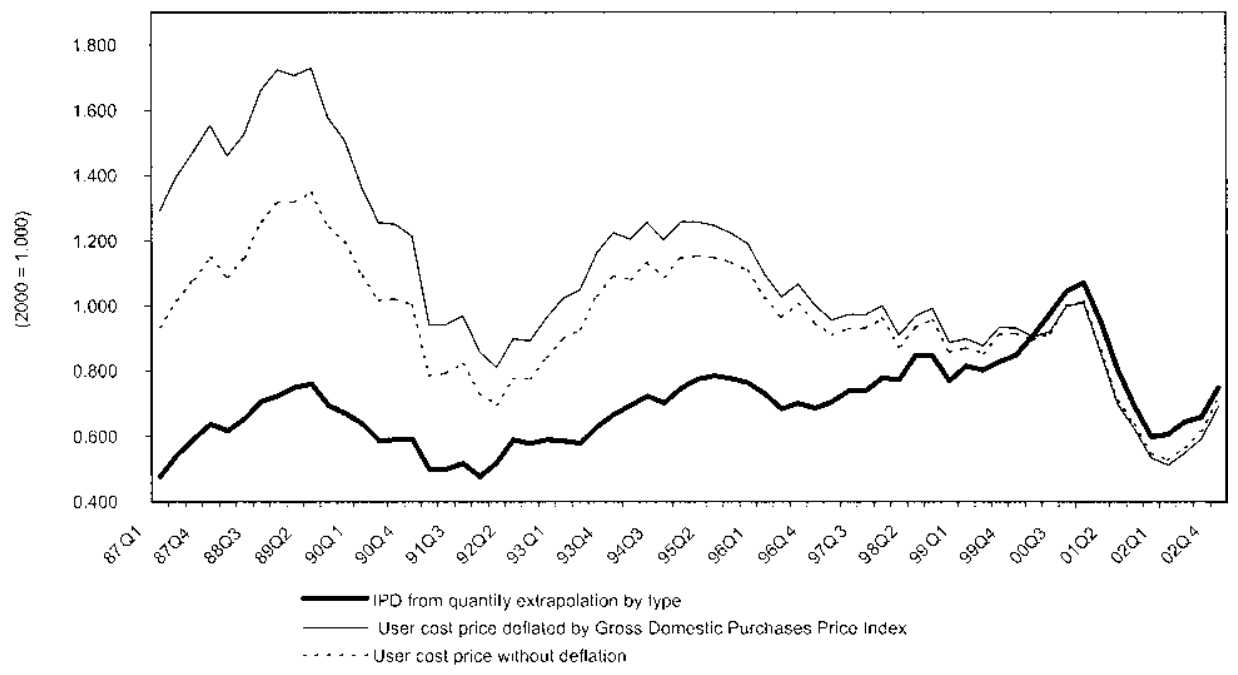

Fig. 6.9 Comparison of borrower service prices: Implicit price deflator versus user cost price 


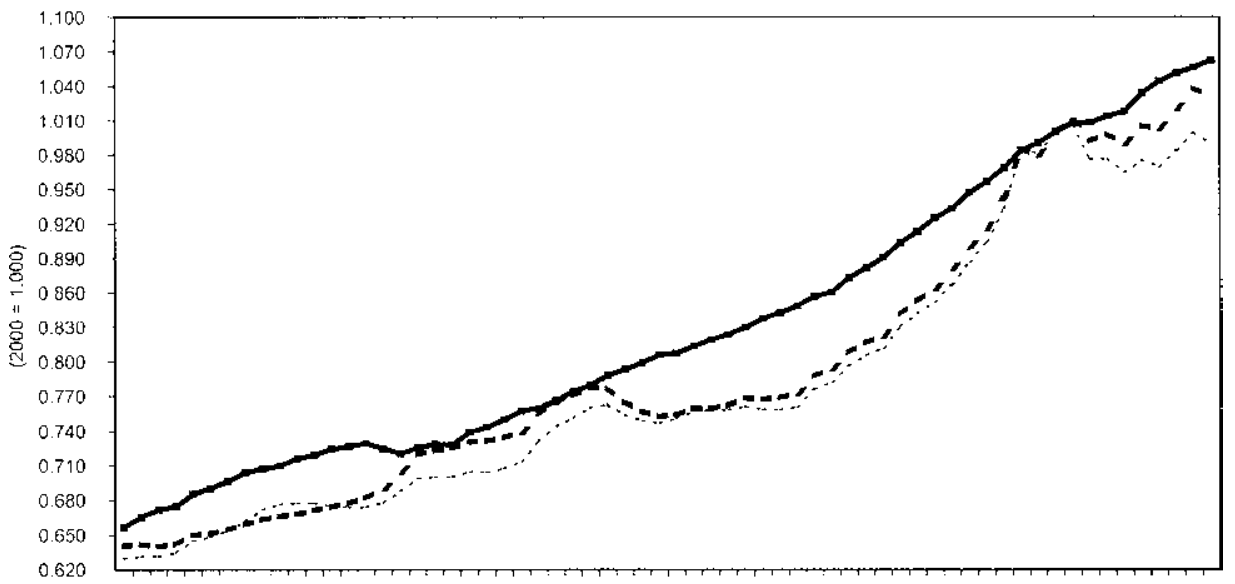

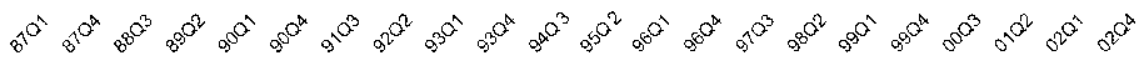

Total PCE cur rent procedure

- Financial services subset. current procedure

—- Total PCE with banks' implicit services via quantity extrapolation by lype

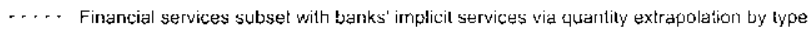

Fig. 6.10 Comparison of fixed-weighted quantity indexes

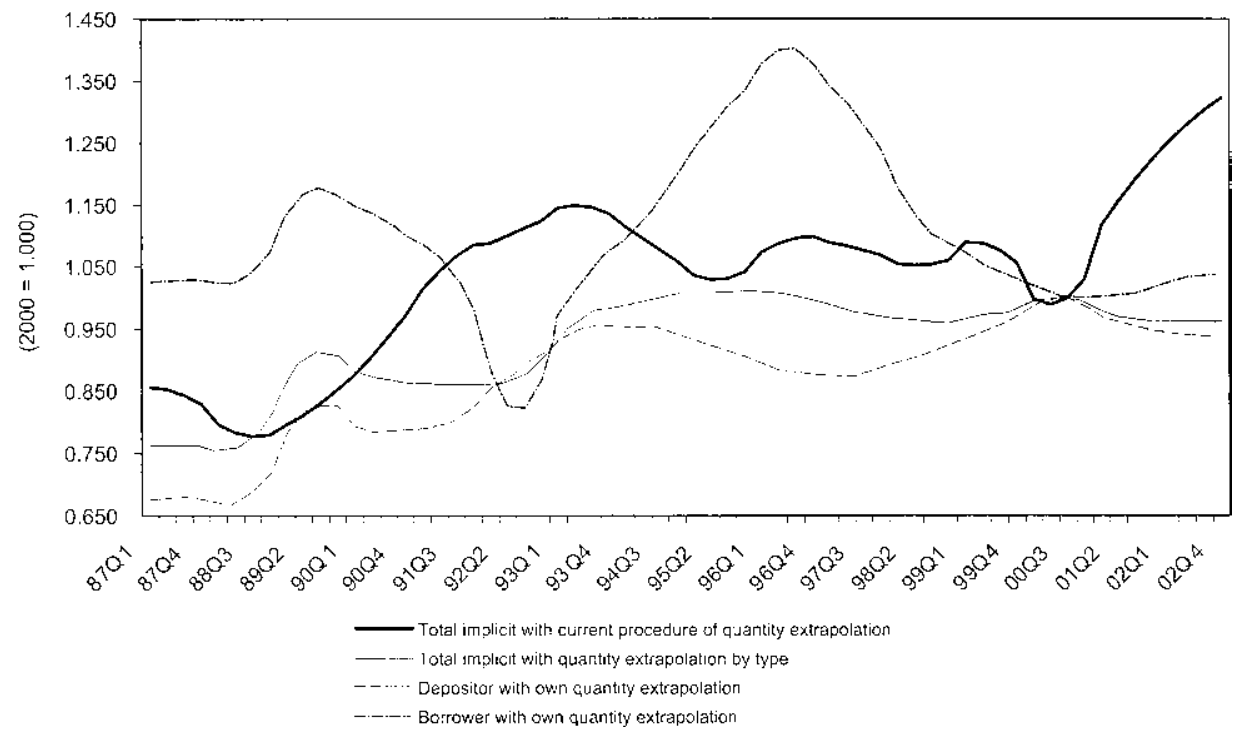

Fig. 6.11 Fixed-weighted quantity indexes banks' implicit services 
quantity indexes for bank implicit services and shows that there is considerably more volatility in the quantity index for borrower services. The total implicit services have similar patterns but note that the large discrepancy that began in 2000Q4 is akin to the difference presented in early 1990s. In the earlier period depositor services increase slightly, and given their higher share of implicit services it makes sense that the implicit services index would increase. The index with the combined quantity extrapolation, the current procedure, gives depositor services a relatively higher weight because, as explained earlier, the deposit share is influenced by the rising user cost of deposits for the period that is illustrated in figure 6.8. The influence of the user cost prices on the shares also explains the divergence in the two total implicit services index in the later period. Starting in 2000Q4, borrower services rise relative to depositor services and this difference in trend is accentuated by the fact that the user cost of borrower services is rising, as illustrated in figure 6.9, while the user cost of depositor services is falling, as illustrated in figure 6.8 .

Figure 6.12 compares the published chained Fisher PCE quantity index with the Törnqvist quantity index - computed implicitly using the Törnqvist price index..$^{33}$ The amount of real implicit depositor services allocated to personal consumption is determined by the proportion of nominal deposit balances owned by persons - the real implicit borrower services allocated to personal consumption is analogously determined. This method of sector allocation is similar to that with the quantity extrapolation by type. Observe that the Törnqvist financial services quantity index does not rise as steadily as the PCE quantity index. The indexes approach each other in 2000 because that is their common base period. Again, the movements in the financial services index do not have much influence on the movement in the overall PCE index because of its relatively small weight.

Figure 6.13 presents the quantity index for bank implicit services and its component depositor and borrower services quantity indexes. Observe that the large differences between the borrower and depositor indexes occurs in the period 1990Q2 to 1992Q1, which includes the 1990 to 1991 recession, and in the period 2000Q4 to 2001Q4, which includes the last recession. In both cases, the beginning is characterized by a falling quantity of implicit borrower services and a rising quantity of implicit depositor services. Figure 6.9 shows that both the implicit price deflator and the user cost price of borrower services are declining in these periods. The implication is that the volume of borrower services did not increase with the fall in borrower services prices. In fact, the growth rate of total consumer credit, as measured by the Flow of Funds, fell continuously in the period 1990 to 1992 and in the

33. For period $t$, the nominal value was deflated by the Törnqvist price index for $t$. This value was then divided by the quantity index for 2000 to obtain a quantity index between periods $t$ and 2000 . 


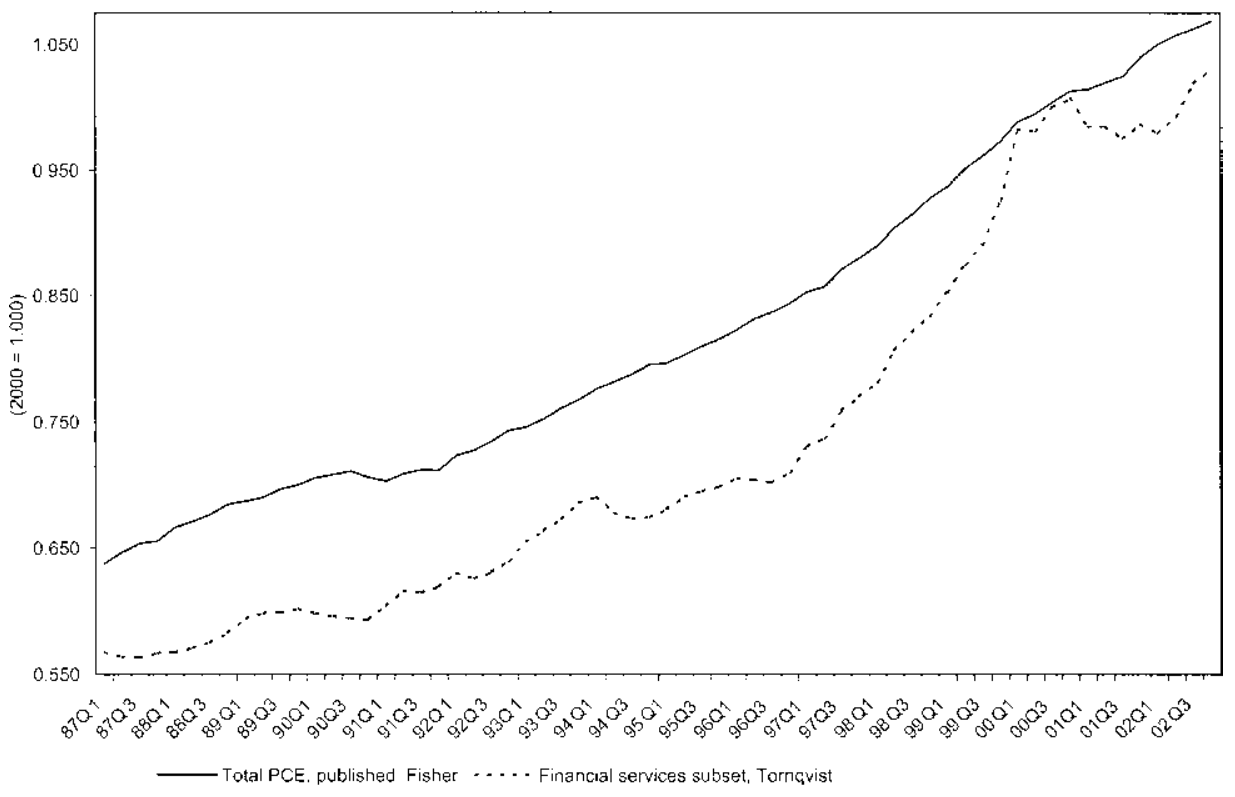

Fig. 6.12 Chain-weighted quantity indexes, PCE and financial services

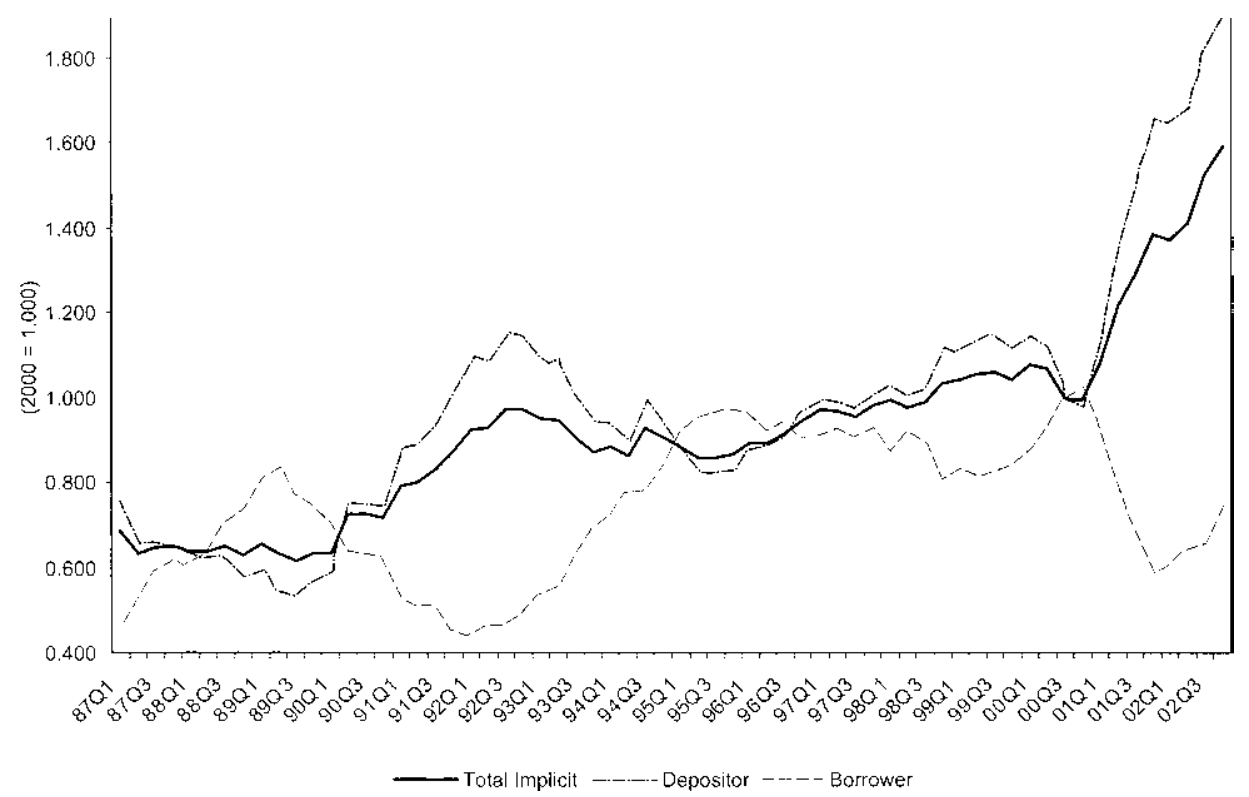

Fig. 6.13 Implicit quantity indexes from Törnqvist price indexes: Total implicit, depositor, and borrower services 
period 2000 to 2002. Regarding the quantity of implicit depositor services, it increases during both of these periods. Figure 6.8 shows that large increases in the user cost price of implicit deposit services occurs in the period 1990Q2 to 1992Q1 and the period 2000Q4 to 2001Q4. The implication is that the volume of deposits did not fall during these periods. Yet, as measured by the Flow of Funds, checkable deposits at commercial banks fell in 1990, increased in 1991 and 1992, fell in 2000 and 2001, and increased in 2002. Thus, the increase in the user cost price of implicit deposit services offset the decrease in checkable deposits when they occurred.

Figure 6.14 compares the different quantity indexes for implicit services from the different implicit service price indexes. In the most recent periods the current procedure leads to an understatement of the quantity of implicit financial services relative to the user cost price index. Observe that the understatement is even greater with the quantity extrapolation by type of service. The difference in the two fixed weighted quantity indexes is due to the influence that changes in user cost prices have on the sector allocations under the current procedure. For example, the large quantity increases under the current procedure immediately after 1988Q3 and 2000Q3 primarily reflect large increases in depositor user costs that flow through to the quantity measures. This movement is not observed with the quantity index that is based

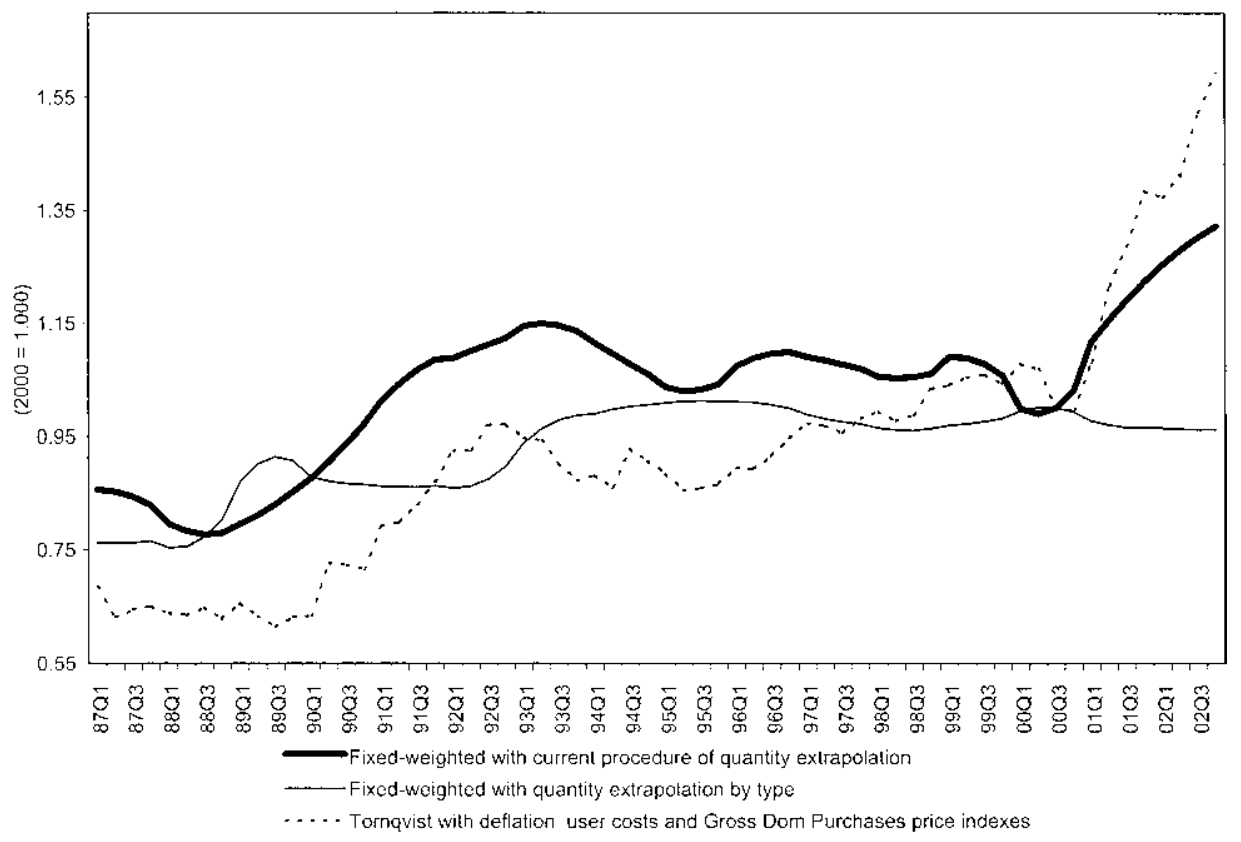

Fig. 6.14 Comparison of quantity indexes for PCE banks' implicit services 
on the extrapolation by type of service because, as discussed earlier, changes in user cost prices do not flow through to the quantity measures.

Given the differences between the quantity indexes derived implicitly via deflation by the Törnqvist price index and directly computed via extrapolation, it is natural to look at differences in the underlying measurement concept. Deflation is used to measure the quantities of services in most cases because services are generally difficult to count. Measuring services by quantity extrapolation focuses on the observable aspect of the transaction and thus may miss unobservable aspects of the service that is being purchased. For example, an individual is purchasing more deposit services with a deposit of ten thousand dollars than with a deposit of one hundred dollars - more safekeeping and record-keeping are being purchased. In the transaction approach, one would only count the deposit and there would be no recording of the amount deposited. Thus, the growth in deposit services illustrated in figure 6.11 (especially in the late 1990s) does not capture any changes in the amount deposited, which is reflected in the depositor services index in figure 6.13.

\subsection{Summary and Conclusions}

The importance of financial services to personal (household) consumption has grown over time. However, the domain of consumer price indexes generally excludes such services if they involve the future generation of income. This chapter maintains that expenditures on such services ought to be included in current consumption because they are outlays for services that are consumed in the period. For example, brokerage fees are payments for services provided at a point in time and similarly a depositor pays for the implicit services attending a deposit in each period that the deposit is maintained. The difficult operational question is how to measure the current period price of the implicit financial services.

The user cost of money approach has been used in several studies of bank output and price measurement and, most recently, by the BEA in the nominal valuation of bank implicit services. In this chapter the user cost based prices of implicit financial services are used to form a price index for bank implicit services, which can then be included in a financial services price index. To illustrate, a financial services price index is constructed from a set of financial services covered in Personal Consumption Expenditures. It is shown that the quantity of implicit financial services using a user cost price measure can be substantially different from the quantity measured using the current BEA procedures for producing quantity indexes for implicit bank services. Given the differences among the quantity indexes, which one is likely to be the most accurate measure? The user cost price based index has two key advantages over the index under the current procedure. First, it directly relates to the user cost prices of the implicit services and thereby 
has a direct link to the nominal value of the implicit services. Second, the data are available quarterly - the quantity extrapolations used in the current method and in the alternative type of service method are based on an annual index provided by the BLS. Currently the Bureau of Labor Statistics is developing a user cost based price measure for banking services that will be part of the Producer Price Index. The BEA is also investigating possible improvements in its price index for implicit bank services.

\section{Appendix}

\section{Using Unit Value Interest Rates}

Unit values rates are used to compute the interest rate components of the user cost price expressions. Because interest rates reflect rates of inflation, it is useful to show how unit value rates can properly account for inflation.

Consider loans $L$ made by a bank in two periods, 0 and 1 . In period 0 let the $r_{0} L_{0}$ denote the interest income and let $r_{0}=\rho_{0}$ (that is, the nominal rate in period 0 is equal to the real rate). In period 1 let the interest income be given by $r_{1} L_{1}$ with $r_{1}=\rho+\pi_{1}$, where $\pi_{1}$ denotes the inflationary expectations in period 1 .

At the end of period 1, assuming that both loans are still on the books, the balance sheet entry for the amount of loans is $L_{0}+L_{1}$ and the interest income is given by $r_{0} L_{0}+r_{1} L_{1}$. Dividing the latter by the former gives the estimate of the interest rate for period 1 :

$$
\begin{aligned}
\hat{r}_{1} & =\frac{r_{0} L_{0}+r_{1} L_{1}}{L_{0}+L_{1}} \\
& =r_{0}\left(\frac{L_{0}}{L_{0}+L_{1}}\right)+r_{1}\left(\frac{L_{1}}{L_{0}+L_{1}}\right) .
\end{aligned}
$$

Writing the nominal interest rate in terms of the real rates yields,

$$
\begin{gathered}
\hat{r}_{1}=\rho\left(\frac{L_{0}}{L_{0}+L_{1}}\right)+\left(\rho+\pi_{1}\right)\left(\frac{L_{1}}{L_{0}+L_{1}}\right) \\
=\rho+\pi_{1}\left(\frac{L_{1}}{L_{0}+L_{1}}\right) .
\end{gathered}
$$

The second equality shows that the estimated interest rate is the real rate plus an adjustment for inflationary expectations that is weighted by the share of loans in the first period. Observe that the weights are nominal, which makes sense given that the estimation is of a nominal rate. Also observe that if there 
were no inflationary expectations in period 1 then the estimated interest rate is the real rate. Generally in the $n$th period,

$$
\hat{r}_{n}=\rho+\sum_{j=1}^{n} \pi_{j}\left(\frac{L_{j}}{\sum_{j=0}^{n} L_{j}}\right) .
$$

Thus the nominal interest estimate in a period is the real rate and assumed to be constant, plus the weighted average of inflationary expectations in each period.

An analogous computation would hold for the liability interest rates and for the reference rate.

The previous interest rate computation, by definition, provides consistency between income and balance sheet data. Furthermore, the nominal interest rate measure provides a consistent measure of the nominal value of implicit services.

The computation of a price index, however, would require the that loan values shown previously be deflated; the idea follows from the use of the loans as an indicator of the volume of activity.

\section{References}

Alchian, A., and B. Klein. 1973. On a correct measure of inflation. Journal of Money Credit and Banking 5 (1): 173-91.

Barnett, W. 1978. The user cost of money. Economics Letters 1 (2): 145-49.

. 1980. Economic monetary aggregates: An application of index number and aggregation theory. Journal of Econometrics 14 (1): 11-48.

- 1995. Exact aggregation under risk. In Social choice, welfare, and ethics: Proceedings of the eighth International Symposium in Economic Theory and Econometrics, ed. W. A. Barnett, H. Moulin, M. Salles, and N. J. Schofield, 353-74. Cambridge: Cambridge University Press.

Chen, B., and D. Fixler. 2003. Measuring the services of property-casualty insurance in the NIPAs: Changes in concepts and methods. Survey of Current Business 83 (October): 10-26.

Diewert, W. E. 1974. Intertemporal consumer theory and the demand for durables. Econometrica 42 (3): 497-516. $115-45$. 1976. Exact and superlative index numbers. Journal of Econometrics 4 (2):

1978. Superlative index numbers and consistency in aggregation. Econometrica 46 (4): 883-900.

Dick, A. 2002. Demand estimation and consumer welfare in the banking industry. Finance and Economic Discussion Series, Federal Reserve Board Discussion Paper no. 2002-58.

Donovan, D. 1978. Modeling the demand for liquid assets: An application to Canada. IMF Staff Papers 25 (December): 676-704.

Fixler, D., M. Reinsdorf, and G. Smith. 2003. Measuring the services of commercial 
banks in the NIPAs: Changes in concepts and methods. Survey of Current Business 83 (9): 33-43.

Fixler, D., and K. D. Zieschang. 1992. User costs, shadow prices, and the real output of banks. In Output measurement in the service sectors, ed. Z. Griliches, 219-43. Chicago: University of Chicago Press.

1999. The productivity of the banking sector: Integrating financial and production approaches to measuring financial service output. The Canadian Journal of Economics 32 (2): 547-69.

- 2001. Price indices for financial services. Paper presented at the April 2001 Ottawa Group meeting. 2-6 April, Canberra, Australia.

International Labour Organization. 2004. Consumer Price Index manual: Theory and practice. (Draft, chapter 10). Available at: http://www.ilo.org/public/english/ bureau/stat/guides/cpi/index.htm.

Kunze, K., M. Jablonski, and M. Sieling. 1998. Measuring output and labor productivity of commercial banks (SIC 602): A transactions-based approach. Paper presented at the Brookings Institution Workshop on Banking Output. 20 November, Washington, DC.

Moulton, B., and E. Seskin. 2003. Preview of the 2003 comprehensive revision of the National Income and Product Accounts: Changes in definitions and classifications. Survey of Current Business 83 (June): 17-34.

National Research Council. 2002. At what price? Conceptualizing and measuring cost of living and price indexes. Panel on Conceptual, Measurement and Other Statistical Issues in Developing Cost of Living Indexes, ed. C. I. Schultz and C. Mackie. Washington, DC: National Academy Press.

Patinkin, D. 1965. Money, interest and prices, 2nd Edition. New York: Harper and Row.

Pollak, R. 1975. The intertemporal cost-of-living index. Annals of Economic and Social Measurement 4 (Winter): 179-85.

Schreyer, P., and P. Stauffer. 2002. Financial services in national accounts: Measurement issues and progress. Organization for Economic Cooperation and Development (OECD) Task Force on Financial Services in the National Accounts.

Schreft, S. 2006. How and why do consumers choose their payment method. Working Paper RWP-06-04, Federal Reserve Bank of Kansas City.

Triplett, J. 2000. Hedonic valuation of "Unpriced" banking services: Application to national accounts and Consumer Price Indexes. Unpublished Manuscript, July. Paper presented at NBER Summer Institute. 10 July, Cambridge, MA.

Woolford, K. 2001. Financial services in the Consumer Price Index. Paper presented at the April 2001 Ottawa Group meeting. 2-6 April, Canberra, Australia.

\section{Comment Susanto Basu}

In this chapter, Fixler takes on a very important and very challenging taskthinking hard about the measure of nominal financial sector output, and decomposing that output into a price index and a volume index. This is a long-standing problem in the economics of measurement, made more urgent

Susanto Basu is a professor of economics at Boston College, and a research associate of the National Bureau of Economic Research. 